\title{
The Influence of Organic Medium and Supports in the Resolution of $(R, S)$-Menthol Catalyzed by Lipases
}

\author{
Julyetty Crystyne da Silva and Maria da Graça Nascimento* \\ Departamento de Química, Universidade Federal de Santa Catarina, \\ 88040-900 Florianópolis-SC, Brazil
}

\begin{abstract}
In this study, various commercial and native lipases, free or immobilized, were used in the enantioselective resolution of $(R, S)$-menthol with vinyl acetate for the preparation of menthyl acetate. Lipase from Candida rugosa (AYL) was found to be the most appropriate. When the reaction was carried out at $35^{\circ} \mathrm{C}$, using $40 \mathrm{mg}$ of AYL and a molar ratio of 1:2 (alcohol:ester), the values for the conversion degree, the enantiomeric excess of the substrate $\left(e e_{s}\right)$ and product $\left(e e_{p}\right)$ and the enantiomeric ratio $(E)$ were $33.6,50.3,>99 \%$ and $>200$, respectively. The results showed that the reaction was more efficient using toluene in comparison with other organic solvents or mixtures of toluene and ionic liquids (ILs). The best support for the AYL immobilization, was corn starch film. This system was used 4 times over 71 days of storage, and menthyl acetate was still obtained with good values of conversion degree, $e e_{s}, e e_{p}$, and $E$.
\end{abstract}

Keywords: lipase, immobilization, starch film, enzymatic kinetic resolution, $(R, S)$-menthol

\section{Introduction}

Biotransformation has been used by mankind for thousands of years. ${ }^{1}$ Lipases (EC 3.1.1.3) are enzymes commonly used in biotransformations and therefore they have been extensively studied. This great interest is mainly because these enzymes are the most commercially available, are associated with the relatively low cost, do not require cofactors and can be used in various reactions. ${ }^{2,3}$

Enzymes are generally active under mild conditions of $\mathrm{pH}(6-8)$ and temperature $\left(20-40{ }^{\circ} \mathrm{C}\right)$. However, it has been reported that in some cases they remain active under extreme conditions of temperature and $\mathrm{pH}$. They can also catalyze a variety of reactions, possess a high degree of selectivity and can be chemo-, regio- and enantioselective. .,4-6 $^{2}$

Although they are excellent catalysts, several factors result in their inactivation, such as their use in an organic medium and certain temperature and $\mathrm{pH}$ conditions. ${ }^{2,7}$ In order to enhance the stability and allow the reuse of the biocatalyst, enzyme immobilization methods are being increasingly studied. ${ }^{4,8,9}$

The main objective of the enzyme immobilization technique is to obtain a biocatalyst with greater thermal stability, stability in organic solvents, higher activity,

*e-mail: maria.nascimento@ufsc.br higher selectivity, reduced inhibition, and ease of recovery and reuse. These characteristics lead to an economically viable process, in particular for the industrial market. ${ }^{4,8,10}$ Different approaches toward immobilizing enzymes have been described. Basically, the methods of immobilization may be divided into four types, namely adsorption on a solid support, entrapment, encapsulation and crosslinking. ${ }^{9-13}$

Natural polymers, such as starch, cellulose, agarose and gelatin, have been used in the preparation of supports for the immobilization of enzymes. These are an attractive alternative from an economic point of view and they can be obtained from renewable sources and are biodegradable, making them more environmentally acceptable..$^{9,14}$

Starch is obtained from renewable sources, besides being biodegradable and of low cost, and thus it is suitable for use as a support for enzyme immobilization. ${ }^{15}$ It can be found in many grains, roots and tubers, and consists essentially of two $\alpha$ - $D$-glucose polymers in varying proportions, amylose and amylopectin. In general, starches exhibit $20-30 \%$ of amylose and $70-80 \%$ of amylopectin. ${ }^{15-18}$

Starch films tend to be brittle and inflexible, requiring the addition of plasticizers, such as sorbitol, to improve the mechanical properties. These films have been used in industry in many areas, such as in the production of food packaging bags from biodegradable wastes, and more recently for lipase immobilization. ${ }^{15,18,19}$ 
The development of methods for preparing enantiomerically pure compounds has been increasingly studied, mainly due to the distinct characteristics of these compounds inside living beings. ${ }^{20,21}$ As previously mentioned, enzymes are enantioselective, which makes them a valuable resource for obtaining these compounds. ${ }^{2,4}$

In addition to the use of enzymes, an alternative that has been widely applied to assist in the resolution of enantiomers is the use of ionic liquids (ILs) as solvents or co-solvents of the reaction. This has demonstrated many advantages, such as high conversion rates, high enantioselectivity, and better enzyme stability since they can form strong hydrogen bonds which can stabilize the enzyme-substrate interactions. This approach also allows a reduction in the associated environmental impacts. ${ }^{22-25}$

Menthol is a compound which can be found in its racemic form. However, the (-)-menthol, an aroma alcohol, is of greater interest, particularly to industry and it is widely applied in food and pharmaceutical sectors, primarily for its cooling and refreshing effects. ${ }^{26,27}$

Therefore, in this study, different lipases immobilized on corn starch film and other supports were used as biocatalysts in the kinetic resolution of $(R, S)$-menthol with vinyl acetate, to obtain enantiomerically pure menthyl acetate (Scheme 1). The effects of using different lipases, organic solvent pure or in mixtures with ILs, types of starch and other supports for the lipase immobilization were investigated along with the possibility for the reuse of the biocatalytic system.

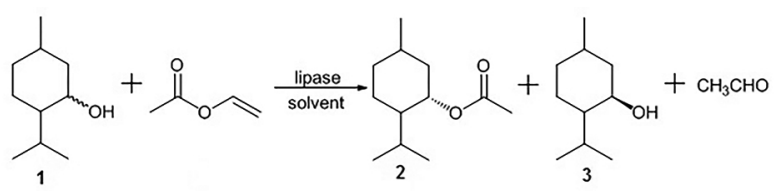

Scheme 1. Enantioselective resolution of $(R, S)$-menthol with vinyl acetate.

\section{Experimental}

\section{Chemicals and lipases}

The solvents 1,4-dioxan (99\%), acetonitrile (99.5\%), acetone $(99.7 \%)$, dichloromethane $(99.5 \%)$, methyl $t$-butyl ether (MTBE) (99.7\%), tert-butyl alcohol (99\%) and heptane (99\%) were obtained from Vetec, chloroform (99.8\%), ethanol (99.5\%), $n$-hexane (98.5\%) and toluene $(99.5 \%)$ were obtained from Synth and ethyl ether (98\%) from Chemis. The solvents were dried using molecular sieves before use. The ionic liquids (ILs) 1-butyl-3-methylimidazolium tetrafluoroborate [BMIM] $\left[\mathrm{BF}_{4}\right](97 \%)$, 1-butyl-3-methyl-imidazolium bromide [BMIM][Br] (99\%), 1-butyl-3-methyl-imidazolium chloride [BMIM] [Cl] (99\%), 1-butyl-3-methylimidazolium hexafluorophosphate $[\mathrm{BMIM}]\left[\mathrm{PF}_{6}\right](96 \%)$ and 1-butyl-3methylimidazolium thiocyanate [BMIM][SCN] $(97 \%)$ were purchased from Fluka. Sorbitol (99\%), poly-vinyl alcohol (99\%) and vinyl acetate (99\%) were purchased from Vetec, $(R, S)$-menthol (99\%) from SAFC, $R$-(+)-menthol (99\%) from Sigma-Aldrich, gelatin from Sigma, corn starch from Duryla-Maisena, agar from ISOFAR, and sago from Lisabor. The loofa sponge (Santa Clara) was acquired in a local store (São Paulo, Brazil) and the starches (obtained from potato, swamp lily, manioc, ginger and pinion) were extracted from their natural sources in the laboratory.

The lipases originating from Burkholderia cepacia PS (BCL) (30,000 $\left.\mathrm{U} \mathrm{g}^{-1}\right)$, Burkholderia cepacia PS-SD (SDL) (30,000 $\left.\mathrm{U} \mathrm{g}^{-1}\right)$, Candida rugosa (AYL) (30,000 $\left.\mathrm{U} \mathrm{g}^{-1}\right)$, Mucor javanicus (MJL) $\left(10,000 \mathrm{U} \mathrm{g}^{-1}\right)$ and Pseudomonas fluorescens (AKL) $\left(25,000 \mathrm{U} \mathrm{g}^{-1}\right)$ were donated by Amano (Japan). The lipase originating from Candida antarctica B (CAL-B) (10,000 PLU g ${ }^{-1}$ immobilized on a polyacrylate resin) was donated by Novozymes (Brazil). The native lipases originating from Aspergillus niger (ANL) (17.2 $\mathrm{U} \mathrm{mL}^{-1}$ ) and Rizopus oligosporus (ROL) (12.6 $\mathrm{U} \mathrm{mL}^{-1}$ ) were donated by Prof Patricia O. Carvalho (USF-Bragança Paulista-Brazil) and the lipase originating from Candida rugosa (CRL) (746 $\mathrm{U} \mathrm{mg}^{-1}$ ) was purchased from Sigma-Aldrich.

Determination of water content in the supports by Karl Fischer titration

The amount of water present in the corn starch film upon evaporation at room temperature was determined by titration using the method of Karl Fischer, based on the quantitative determination of water in a anhydrous solution of sulfur dioxide and iodine (633 Automatic titrator Karl Fischer Metrohm AG CH-9100 Herisau). ${ }^{28}$

Preparation of corn starch film and immobilization of lipases by entrapment

Firstly, $0.7 \mathrm{~g}$ of corn starch and $0.3 \mathrm{~g}$ of sorbitol were placed in a $50 \mathrm{~mL}$ beaker. The mixture was then dissolved in $15 \mathrm{~mL}$ of distilled water. The solution formed was kept under magnetic stirring at a temperature of approximately $100{ }^{\circ} \mathrm{C}$ for $35 \mathrm{~min}$. After cooling (to room temperature) $40 \mathrm{mg}$ of lipase was added and the system was stirred for another $10 \mathrm{~min}$. The solution was transferred to a Petri dish and placed in a fume chamber for water evaporation (ca. $24 \mathrm{~h}$ ). The film containing the immobilized enzyme was then cut into small pieces and transferred to $50 \mathrm{~mL}$ 
Erlenmeyer flasks containing organic solvent. The samples were then ready to be used in the reactions. The amount of water in the film was $3 \%$.

The same procedure was used for the preparation of films with different starches, gelatin and poly-vinyl alcohol (PVA). Supports containing $\mathrm{TiO}_{2}$ and $\mathrm{Al}_{2} \mathrm{O}_{3}$ nanotubes were prepared with 0.2 to $0.5 \%(\mathrm{~m} / \mathrm{v})$ of nanotubes, $3.3 \%(\mathrm{~m} / \mathrm{v})$ PVA and $40 \mathrm{mg}$ AYL.

Immobilization of lipase in agar gel by entrapment

Firstly, $0.4 \mathrm{~g}$ of agar and $1 \mathrm{~mL}$ of water were placed in a $100 \mathrm{~mL}$ beaker and the system was left in an ultrasonic bath for $3 \mathrm{~min}$. After this time, $8 \mathrm{~mL}$ of boiling water (ca. $100{ }^{\circ} \mathrm{C}$ ) was added. When the mixture became a transparent gel it was allowed to reach a temperature of approximately $30^{\circ} \mathrm{C}$ and $40 \mathrm{mg}$ of AYL dissolved in $2 \mathrm{~mL}$ of water was then added. After cooling, a consistent gel was obtained and with a spatula this was passed through a sieve, forming small pieces of agar gel containing the enzyme. The gel pieces were stored in organic solvent for later use. A similar procedure was used to immobilize lipase originating from Rhizopus oryzae (F-AP15). ${ }^{29}$

\section{Immobilization of lipase by physical absorption}

Firstly, the loofa sponge (LS) ( $0.5 \mathrm{~g})$ was placed in a solution of $\mathrm{H}_{2} \mathrm{O}_{2}$ for $24 \mathrm{~h}$, dried and cut into small disks (ca. $1 \mathrm{~cm}^{3}$ ). Next, $40 \mathrm{mg}$ of AYL was added to $25 \mathrm{~mL}$ of phosphate buffer solution ( $\mathrm{pH}$ 7.2). The solution was placed on the loofa sponge in a Petri dish and allowed to dry at room temperature.

The sago $(1 \mathrm{~g})$ was placed in a $10 \mathrm{~mL}$ beaker, and $40 \mathrm{mg}$ of AYL dissolved in $2 \mathrm{~mL}$ of potassium phosphate buffer (pH 7.2) was added. The aqueous solution was absorbed by the sago. The support with the immobilized lipase was then ready to be stored in organic solvent and used in the reactions.

General procedure for enzymatic kinetic resolution of $(R, S)$-menthol

For the resolution reaction, $(R, S)$-menthol $(3 \mathrm{mmol})$ and vinyl acetate (in different proportions) were placed in a $50 \mathrm{~mL}$ Erlenmeyer flask containing the free or immobilized lipase and the organic solvent pure or in mixtures with ILs $(20 \mathrm{~mL})$. The reaction mixture was placed in a thermostatic bath with orbital shaking (Marclabor) at a predetermined temperature. Aliquots were withdrawn periodically for analysis by gas chromatography. Details for each reaction will be described in the Results and Discussion section.

\section{Analytical methods}

The analysis was performed by gas chromatography (GC) (Agilent Technologies 7820A) with a chiral stationary phase and flame ionization detection. The separation was performed using a Varian-CP-chiral Dex CB $(25 \mathrm{~m} \times 0.25 \mathrm{~mm} \times 0.25 \mu \mathrm{m})$ column. The chromatographic analysis was performed at $125^{\circ} \mathrm{C}$ for $20 \mathrm{~min}$. The injector (split 1:100) and detector temperatures were set at $230{ }^{\circ} \mathrm{C}$ and the gas pressure was 13 psi resulting in an analysis time of $6 \min \left(\mathbf{1 ~ R}_{\mathrm{t}}=4.8-4.9 \mathrm{~min}, \mathbf{3} \mathrm{R}_{\mathrm{t}}=4.2-4.4 \mathrm{~min}\right)$.

Based on the difference in the relative peak areas of the enantiomers of $(R, S)$-menthol and menthyl acetate it was possible to calculate the enantiomeric excess of the substrate $\left(e e_{s}\right)$ and product $\left(e e_{p}\right)$. These values, in combination with the degree of conversion, were used to calculate the enantiomeric ratio $(E)$ of the reaction. ${ }^{2}$

The absolute configuration of the product was determined by comparison with the ester $\left(\mathrm{R}_{\mathrm{t}}=4.4 \mathrm{~min}\right)$ obtained using standard $(R)$-menthol $\left(\mathrm{R}_{\mathrm{t}}=4.9 \mathrm{~min}\right)$.

\section{Results and Discussion}

\section{Lipase screening}

In a first approach, six commercially available lipases and two native lipases were used for the stereoselective transesterification of $(R, S)$-menthol with vinyl acetate as the acyl donor, using $40 \mathrm{mg}\left(2 \mathrm{~g} \mathrm{~L}^{-1}\right)$ of the lipases SDL, AYL, AKL, MJL, CRL, ANL, ROL and CALB. The reactions were carried out using $(R, S)$-menthol $(3 \mathrm{mmol})$ and vinyl acetate $(6 \mathrm{mmol})$ in toluene $(20 \mathrm{~mL})$ at $30^{\circ} \mathrm{C}$. Toluene was selected based on a previous study by Brady et al. ${ }^{26}$ The reaction was monitored by chiral-CG at different times (24, $48,72,96$ and $168 \mathrm{~h}$ ). In this study, most of the lipases were used in their free form, except CALB which was acquired immobilized. The results are presented on Table 1.

Using the non-commercial lipases ROL, ANL and the commercial SDL, no product was detected until $168 \mathrm{~h}$ of reaction. Using CALB and MJL, the product was detected only after $96 \mathrm{~h}$ of reaction, with degrees of conversion of 19.8 and $19.6 \%$ and $e e_{s}$ values of 24.7 and $24.4 \%$, respectively. No significant improvement in the conversion or the $e e_{s}$ values was observed after $168 \mathrm{~h}$ of reaction.

Using the lipases AYL, AKL and CRL, the $(R)$-ester was detected with in $24 \mathrm{~h}$ of reaction (results not presented on Table 1). With the use of AYL, the degrees of conversion were 17.3, 19.1 and $22.3 \%$ and the $e e_{s}$ values were 20.8, 23.6 and $28.6 \%$ after 48,96 and $168 \mathrm{~h}$, respectively. When AKL was used, the degrees of conversion were of 16.3, 17.9 and $18.9 \%$ and the $e e_{s}$ values were $19.2,21.7$ and $23.2 \%$ after 48 , 
Table 1. Lipase screening applied in the resolution of $(R, S)$-menthol ${ }^{\mathrm{a}}$

\begin{tabular}{|c|c|c|c|c|c|c|c|c|c|c|}
\hline \multirow{2}{*}{ entry } & \multirow{2}{*}{ Lipase } & \multicolumn{3}{|c|}{$48 \mathrm{~h}$} & \multicolumn{3}{|c|}{$96 \mathrm{~h}$} & \multicolumn{3}{|c|}{$168 \mathrm{~h}$} \\
\hline & & $\mathrm{c} / \%$ & $e e_{s} / \%$ & $E$ & $\mathrm{c} / \%$ & $e e_{s} / \%$ & $E$ & $\mathrm{c} / \%$ & $e e_{s} / \%$ & $E$ \\
\hline 1 & AYL & 18.9 & 20.5 & $>200$ & 19.1 & 23.6 & $>200$ & 22.3 & 28.6 & $>200$ \\
\hline 2 & $\mathrm{AKL}$ & 16.3 & 19.2 & $>200$ & 19.7 & 21.7 & $>200$ & 18.9 & 23.2 & $>200$ \\
\hline 3 & MJL & - & 20.6 & - & 19.6 & 24.4 & $>200$ & 22.4 & 28.8 & $>200$ \\
\hline 4 & CRL & 14.2 & 16.4 & $>200$ & 19.3 & 23.7 & $>200$ & 18.8 & 23.0 & $>200$ \\
\hline 5 & CALB & - & 15.0 & - & 19.8 & 24.7 & $>200$ & 21.7 & 27.6 & $>200$ \\
\hline
\end{tabular}

${ }^{a}$ Reaction conditions: $(R, S)$-menthol $(3 \mathrm{mmol})$, vinyl acetate $(6 \mathrm{mmol}), 30^{\circ} \mathrm{C}, 40 \mathrm{mg}$ lipase, $20 \mathrm{~mL}$ toluene; (-): not detected; conversion (c), enantiomeric excess of the substrate $\left(e e_{s}\right)$ and enantiomeric ratio $(E)$ determined by GC; AYL: Candida rugosa; AKL: Pseudomonas fluorescens; MJL: Mucor javanicus; CRL: Candida rugosa; CALB: Candida antartica.

96 and $168 \mathrm{~h}$, respectively. The reaction with CRL provided conversions of $14.2,19.3$ and $18.8 \%$ and $e e_{s}$ values of 16.4 , 23.7 and $23.0 \%$ after 48,96 and $168 \mathrm{~h}$, respectively.

In all reactions and regardless of the lipase and reaction time used, the $(R)$-ester was obtained with $e e_{p}$ and $E$ values of $>99 \%$ and $>200$, respectively, which is considered ideal for enzymatic resolution.

Brady et $a l .{ }^{26}$ also used various lipases in the enantiosselective transesterification of $(R, S)$-menthol with vinyl acetate. In that study, the lipases from $R$. miehei, C. antarctica, C. antarctica A, Chromobacterium viscosum and Pseudomonas cepacia presented some catalytic activity when toluene was used as a solvent.

Thus, considering the above results, the commercial lipases AYL and AKL were selected to evaluate the influence of immobilization in starch film.

\section{Influence of lipase immobilization}

In this next study, the lipases AYL and AKL were immobilized in corn starch film and used in the resolution of $\mathbf{1}$ with vinyl acetate, at $30^{\circ} \mathrm{C}$ in toluene. The samples were analyzed at different times $(24,48,72,96$ and $168 \mathrm{~h})$ by chiral-GC. For comparison, the same reactions were carried out with the film in the absence of the lipases, and no product was detected. In addition, after $168 \mathrm{~h}$ of reaction no macroscopic changes in the corn starch film were observed, verifying the good stability of this material when used as a support for lipases.

On using immobilized AKL as catalysts, no $(R)$-ester (3) was detected until $168 \mathrm{~h}$ of reaction. The interaction of these lipases with the support was probably not favorable and led to some enzyme inactivation. However, the use of immobilized AYL provided good results (Figure 1).

As can be observed in Figure 1, only small variations in the values for the conversion degree and $e e_{s}$ were observed during the reaction time, these being in the range of $17.8-19.3 \%$ and $15.2-16.2 \%$, respectively. It should be

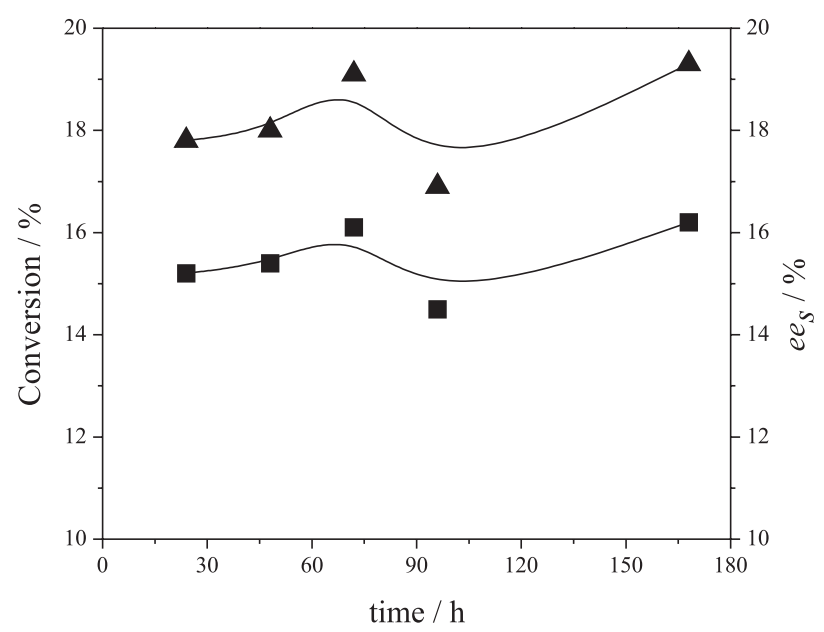

Figure 1. Variation in the degree of conversion and $e e_{s}$ for $\mathbf{3}$ as a function of time using AYL immobilized in starch film as the catalyst: (ם) conversion; (A) $e e_{s}\left[(R, S)\right.$-menthol $(3 \mathrm{mmol})$, vinyl acetate $(6 \mathrm{mmol}), 30^{\circ} \mathrm{C}, 2 \mathrm{~g} \mathrm{~L}^{-1}$ of AYL and toluene $(20 \mathrm{~mL})]$.

noted that the ( $R$ )-ester was obtained with $e e_{p}$ and $E$ values $>99 \%$ and $>200$, respectively, results which were similar than those obtained when free lipases were used as catalysts.

In general, both the conversion degree and $e e_{s}$ values were lower than those obtained using free AYL (see data presented on Table 1, entry 1). However, the use of the immobilized lipase offers some aspects of greater interest, that is, it protects the biocatalyst from the reaction medium, maintains the enzyme activity and allows the reuse of the system. ${ }^{7,8,11,13}$

Wang et al. ${ }^{30}$ performed the resolution of $(R, S)$-menthol using various lipases, acyls donors and supports for immobilization. The results showed that when the reaction was carried out using valeric acid as a donor acyl and lipase from Candida rugosa immobilized in DEAR-Sephadex A-25 as catalyst, the conversion, $e e_{p}$ and $E \%$ values were of 44,95 and $87 \%$, respectively. These values were very similar to those obtained when the reaction with the lipase in the free form was realized (conversion, $e e_{p}$ and $E \%$ of 45,95 and $92 \%$, respectively). 
In order to improve the conversion degrees and $e e_{s}$, a reaction time of $48 \mathrm{~h}$ and AYL were selected for use in the subsequent experiments. These included an assessment of the use of organic solvent pure or in mixtures with ionic liquids (ILs) and the use of other supports. In addition, the potential for the reuse of the biocatalytic system was investigated.

\section{Effect of the reaction medium}

In this study, eleven pure organic solvents with different polarities and mixtures of toluene with imidazolium ILs (toluene:ILs 9:1 v/v) were screened to evaluate their influence on the resolution of $(R, S)$-menthol at $35^{\circ} \mathrm{C}$. The choice of the solvent mixture composition and temperature were based in previous works. ${ }^{19,24}$

In Figure 2, the results for the degrees of conversion and $e e_{s}$ are reported for the reactions conducted using the solvents pure or in mixtures with the different ILs, in which the product was detected. These exhibited $e e_{p}$ and $E$ values of $>99 \%$ and $>200$, respectively.

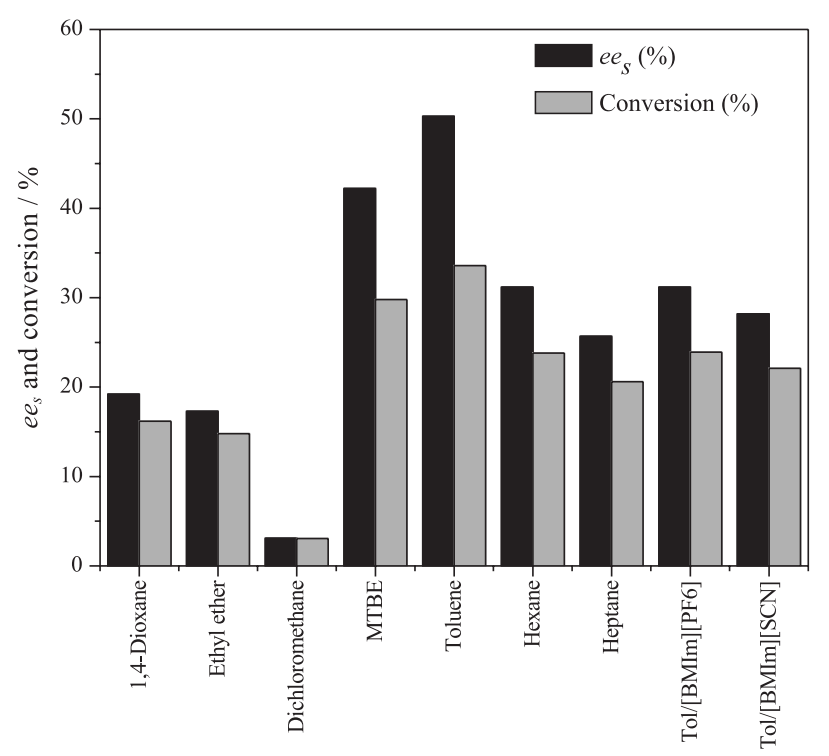

Figure 2. Influence of the reaction medium on the resolution of $(R, S)$-menthol $\left[(R, S)\right.$-menthol $(3 \mathrm{mmol})$, vinyl acetate $(6 \mathrm{mmol}), 35^{\circ} \mathrm{C}$, $2 \mathrm{~g} \mathrm{~L}^{-1} \mathrm{AYL}, 48 \mathrm{~h}$ and $20 \mathrm{~mL}$ solvent].

As can be observed in Figure 2, when 1,4-dioxane ( $\log P=-1.1)$, ethyl ether $(\log P=0.83)$ and dichloromethane $(\log P=0.93)$ were used the degrees of conversion were $16.2,14.8$ and $30.6 \%$ and the $e e_{s}$ values were 19.2, 17.3 and $3.1 \%$, respectively. When the reaction was carried out in the presence of MTBE $(\log P=1.43)$, toluene $(\log P=2.5$ ), $n$-hexane $(\log P=3.5)$ and heptane $(\log P=4.0)$ the degrees of conversion were 29.8, 33.6, 23.8 and $20.6 \%$ and the $e e_{s}$ values were $42.2,50.3,31.2$ and $25.7 \%$, respectively.
When acetonitrile $(\log P=-0.33)$, ethanol $(\log P=-0.24)$, acetone $(\log P=-0.23)$ and chloroform $(\log P=2.0)$ were used, the formation of the product $\mathbf{3}$ was not detected, indicating that these solvents in some way influenced the structure of AYL causing inactivation, or they were not effective in solubilizing the reagents, thus hindering the reaction.

It is well established in the literature ${ }^{31,32}$ that the enzyme activity is strongly influenced by the choice of organic solvent. Several studies have shown that the reactions carried out using solvents with $\log P>4.0$ tend to be more efficient, since these solvents can trap the water around the enzyme creating a micro-aqueous layer. This microenvironment can help to maintain the active conformation of the lipase and thus preserve its catalytic activity. Another explanation for these results is that more polar solvents tend to alter the amount of water needed for the enzyme to maintain its catalytic activity. ${ }^{24,31,32}$

This effect was clearly noted on analyzing the data obtained. In summary, when solvents with $\log P \leq 0.93$ were used the reaction did not occur or the $e e_{s}$ values were $<20 \%$. With the use of solvents with $\log P \geq 1.43$ the reaction was more selective, presenting degrees of conversion and $e e_{s}$ values of up to $33 \%$. An unexpected result was obtained when chloroform was used, where no ester was detected.

Ionic liquids are increasingly used as reaction media in organic chemistry since they offer a wide range advantages over classical organic solvents. Basically, the interest in using ionic liquids in biocatalysis is the desire to replace volatile organic solvents by non-volatile ionic liquids. ${ }^{33,34}$ To evaluate these possible effects, mixtures of toluene:[BMIM][X] 9:1 (v/v), where $\mathrm{X}=\mathrm{BF}_{4}^{-}, \mathrm{Cl}^{-}, \mathrm{Br}^{-}$, $\mathrm{SCN}^{-}$and $\mathrm{PF}_{6}^{-}$, were used.

When mixtures of toluene with the ILs 1-butyl-3-methylimidazolium tetrafluoroborate [BMIM] $\left[\mathrm{BF}_{4}\right], 1$-butyl-3methyl-imidazolium chloride [BMIM][Cl] and 1-butyl3-methyl-imidazolium chloride [BMIM][Br] were used, the formation of the product $\mathbf{3}$ was not detected. However, when mixtures of toluene with the ILs $[\mathrm{BMIm}]\left[\mathrm{PF}_{6}\right]$ and $[\mathrm{BMIm}][\mathrm{SCN}](9: 1 \mathrm{v} / \mathrm{v})$ were used, the degrees of conversion were 31.2 and $22.1 \%$ and the $e e_{s}$ values were 31.2 and $28.2 \%$, respectively. The best result achieved with the use of $[\mathrm{BMIm}]\left[\mathrm{PF}_{6}\right]$ can be explained considering that this ionic liquid is considered more apolar, and thus, more suitable for use in enzymatic catalysis. ${ }^{23,34,35}$

A comparison of the use of the ILs as co-solvents with the use of toluene showed that the reactions presented higher degrees of conversion and $e e_{s}$ values in the presence of the pure organic solvent. These results can be attributed to several factors. The five ILs employed for the current study have distinctly different properties in 
terms of hydrophobicity, polarity, anion nucleophilicity, hydrogen bonding basicity and viscosity. Since these properties influence the conformation of the lipases and their reactivity, these are of primary concern. ${ }^{34-36}$ The ILs can also interact with the support in which the AYL was immobilized, possibly hindering the interaction between the enzyme and the reaction medium.

Yuan et al..$^{37}$ tested several solvents in the resolution of $(R, S)$-menthol with propionic anhydride using lipase from Candida rugosa as catalyst. The results showed that the conversion was greater when solvents with higher $\log P$, such as 1-hexane $(\log P=3.5)$, heptane $(\log P=4.0)$ and octane ( $\log P=4.5$ ) were used, forming the product in conversion values ca. $50 \%$. By using the IL $[\mathrm{BMIm}]\left[\mathrm{PF}_{6}\right]$ as solvent, the conversion, $e e_{p}$ and $E$ values were similar to those obtained with pure 1-hexane.

Influence of the support used for the immobilization of AYL

Lipases, and other enzymes, can be immobilized on various supports and this process can affect the catalytic activity due to the different interactions. In addition, the support may interfere with the reactions studied due to several factors, including the diffusion of reagents and products. ${ }^{3,10,11,13}$

Thus, to evaluate the effect of using immobilized AYL in the resolution of $(R, S)$-menthol, different materials such as starch (corn, potato, swamp lily, manioc, ginger and pinion), poly-vinyl alcohol (PVA), gelatin, $\mathrm{TiO}_{2}$ or $\mathrm{Al}_{2} \mathrm{O}_{3}$ nanoparticles impregnated in PVA films, sago, agar gel or loofa sponge were used as the support, and toluene as organic solvent. The results are reported in Figure 3.

For all reactions, the $e e_{p}$ and $E$ values were $>99 \%$ and $>200$, respectively. As can be observed in Figure 3, when AYL was immobilized in the films formed with corn, swamp lily and ginger starches, the reactions were more efficient, with degrees of conversion of 33.6, 26.1 and $24.2 \%$ and $e e_{s}$ values of 50.3, 25.9 and $31.7 \%$, respectively.

Using AYL immobilized in potato, manioc and pinion starch films, the reactions showed moderate degrees of conversion (20.1, 19.5 and $20.3 \%$, respectively), while the $e e_{s}$ values were $25.9,24.1$ and $25.3 \%$, respectively. Good results were also achieved using various lipases immobilized in ginger starch film in the resolution of 1-phenylethanol, presenting in the most cases $e e_{p}$ and $E$ values of $>99 \%$ and $>200$, respectively. ${ }^{19}$

When PVA, gelatin and $\mathrm{TiO}_{2}$ or $\mathrm{Al}_{2} \mathrm{O}_{3}$ nanoparticles in PVA films were used as supports for AYL, the degrees of conversion were $22.8,17.5,19.6$ and $15.1 \%$, respectively and the $e e_{s}$ values were $29.5,21.2,24.4$ and $17.6 \%$, respectively.

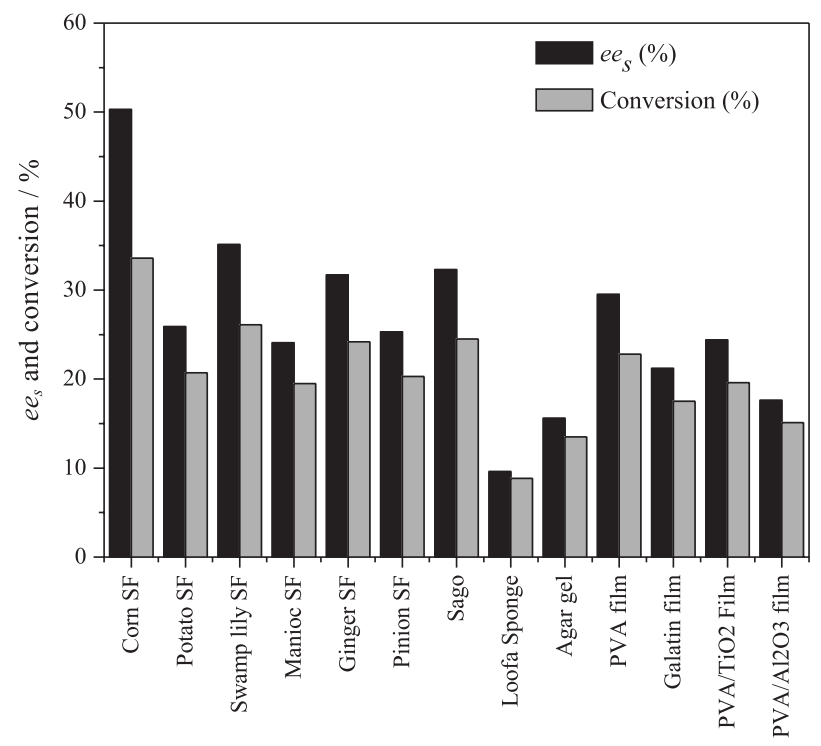

Figure 3. Effect of using different starches and materials for the immobilization of AYL in the resolution of $(R, S)$-menthol $[(R, S)$-menthol (3 mmol), vinyl acetate $(6 \mathrm{mmol}), 35^{\circ} \mathrm{C}, 2 \mathrm{~g} \mathrm{~L}^{-1} \mathrm{AYL} 48 \mathrm{~h}$ and $20 \mathrm{~mL}$ toluene; $\mathrm{SF}=$ starch film].

In the reactions carried out with AYL immobilized in sago, loofa sponge and agar gel, the degrees of conversion were $24.5,8.8$ and $13.5 \%$, respectively, and the $e e_{s}$ values were $32.5,9.6$ and $15.6 \%$, respectively. Of these supports, sago was the most efficient and this finding may be related to the different methodology used for the support preparation and AYL immobilization. When loofa sponge was used, some desorption of AYL may have occurred, and thus both conversion degree and $e e_{s}$ values were low. Agar gel was the system which contains the highest amount of water $(81 \%)$, and this may have contributed to the low selectivity of the reaction, since the presence of this solvent can hinder the diffusion of the reactants and products. Similar results have been reported recently for the preparation of 1-octyl acetate and 1-pentyl octanoate. ${ }^{24}$

Thus, of the supports tested, the most efficient was the film produced from corn starch.

\section{Reuse of the biocatalyst system}

One of the main advantages of immobilizing enzymes is the reusability of the biocatalyst. Thus, to evaluate the efficiency of using immobilized AYL in corn starch film, the resolution of $(R, S)$-menthol was performed applying five cycles over a period of 71 days. The results are reported in Figure 4. After completion of each run, the catalyst was filtered, washed with toluene, storage at room temperature and reused under similar conditions.

In the second use, the degrees of conversion and $e e_{s}$ values decreased moderately (to 33.2 and $24.9 \%$, 


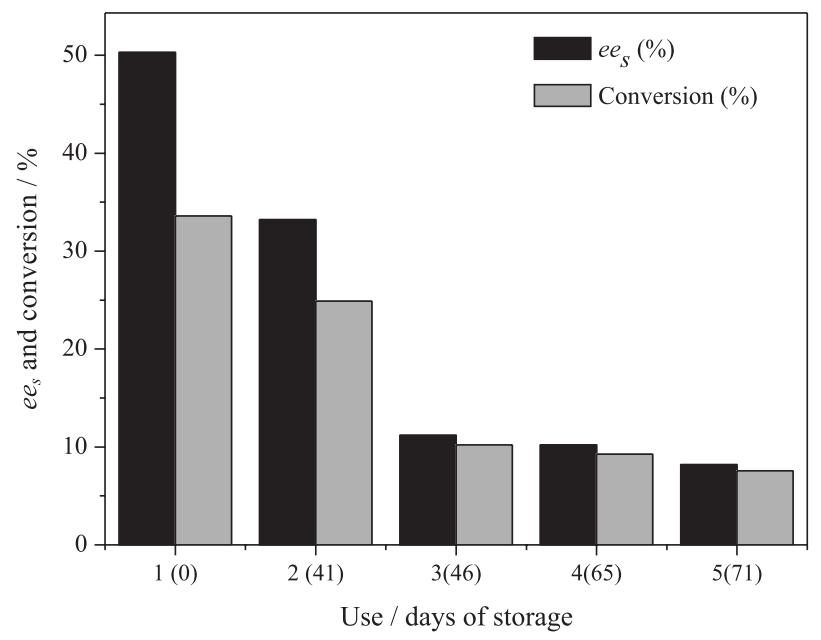

Figure 4. Effect of reuse and days of storage of the biocatalyst (AYL) immobilized in starch film in the resolution of $(R, S)$-menthol $\left[(R, S)\right.$-menthol (3 mmol), vinyl acetate $(6 \mathrm{mmol}), 35^{\circ} \mathrm{C}, 2 \mathrm{~g} \mathrm{~L}^{-1} \mathrm{AYL} 48 \mathrm{~h}$ and $20 \mathrm{~mL}$ toluene].

respectively) after 41 days of storage of the biocatalyst at room temperature in the presence of toluene. In the third, fourth and fifth uses, the degrees of conversion were 10.2, 9.3 and $7.5 \%$ and the $e e_{s}$ values were $11.2,10.2$ and $8.2 \%$, after 46, 65 and 71 days of storage, respectively.

On analyzing the results, a decrease was observed in the degrees of conversion and $e e_{s}$ values in the second use after 41 days of storage, and also in the third use after 46 days. As mentioned, the lipase immobilization method, in this study, was adsorption. Therefore, the obtained results can be explained considering that some lipase was released to the reaction medium, causing a possible inactivation of the biocatalyst. Nevertheless, these results are still satisfactory, since in all reactions the $e e_{p}$ and $E$ values were $>99 \%$ and $>200$, respectively.

These data demonstrate that the immobilization of AYL in corn starch film is an attractive option since, besides protecting the lipase from the organic solvent, the lipase catalytic activity is maintained after 71 days of storage. It should be noted that during this period no macroscopic changes in the film were observed, which represents a further advantage of this immobilization methodology.

\section{Conclusions}

The data obtained in the resolution of $(R, S)$-menthol with vinyl acetate, showed that of the lipases and supports tested, AYL and corn starch film were the most efficient. The method used for the immobilization caused only a small decrease in the enzyme activity. Of the solvents tested, toluene was found to be ideal. The use of various ILs as cosolvents in mixtures with toluene provided no improvement in the selectivity of the reaction. The possibility of the reuse (four times) of the biocatalyst showed that the immobilization was an efficient methodology in which the AYL was protected and the catalytic activity maintained after 71 storage days. The $E$ and $e e_{p}$ values remained at $>200$ and $>99 \%$, results which are satisfactory for enzymatic resolution.

\section{Acknowledgments}

This study was supported by the Universidade Federal de Santa Catarina (UFSC-Brazil), Conselho Nacional de Desenvolvimento Científico e Tecnológico (CNPq-Brazil), CAPES and INCT-Catalysis which provided financial support and scholarship (J. C. S). We are also grateful to Amano Pharmaceutical Co. (Japan), Novozymes (Brazil) and Prof Patricia O. Carvalho (USF-Bragança Paulista-Brazil) for donating the non-commercial lipases, to Prof Cristiane Pilissão (UFTPR-Curitiba-Brazil) for the preparation of films with nanotubes and Prof Ademir F. Morel (UFSM-RSBrazil) for the donation of the standard $(R)$-menthol.

\section{References}

1. Leresche, J. E.; Meyer, H.-P.; Org. Process Res. Dev. 2006, 10, 572.

2. Faber, K.; Biotransformations in Organic Chemistry, $6^{\text {th }}$ ed.; Springer Berlin Heidelberg: Berlin, 2011.

3. Sharma, R.; Chisti, Y.; Banerjee, U. C.; Biotechnol. Adv. 2001, $19,627$.

4. Drauz, K.; Gröger, H.; May, O.; Waldmann, H.; Enzyme Catalysis in Organic Synthesis, Vol. 1; Wiley-VCH Verlag: Weinheim, 2012.

5. Haki, G.; Bioresour. Technol. 2003, 89, 17.

6. Kapoor, M.; Gupta, M. N.; Process Biochem. 2012, 47, 555.

7. Milner, S. E.; Arkivoc 2012, 2012, 321.

8. Mateo, C.; Palomo, J. M.; Fernandez-Lorente, G.; Guisan, J. M.; Fernandez-Lafuente, R.; Enzyme Microb. Technol. 2007, 40,1451 .

9. Sheldon, R. A.; van Pelt, S.; Chem. Soc. Rev. 2013, 42, 6223.

10. Liese, A.; Hilterhaus, L.; Chem. Soc. Rev. 2013, 42, 6236.

11. Adlercreutz, P.; Chem. Soc. Rev. 2013, 42, 6406.

12. Stepankova, V.; Bidmanova, S.; Koudelakova, T.; Prokop, Z.; Chaloupkova, R.; Damborsky, J.; ACS Catal. 2013, 3, 2823.

13. dos Santos, J. C. S.; Barbosa, O.; Ortiz, C.; Berenguer-Murcia, A.; Rodrigues, R. C.; Fernandez-Lafuente, R.; ChemCatChem 2015, 7, 2413.

14. Cantone, S.; Ferrario, V.; Corici, L.; Ebert, C.; Fattor, D.; Spizzo, P.; Gardossi, L.; Chem. Soc. Rev. 2013, 42, 6262.

15. Halley, P. J.; Avérous, L.; Starch Polymers: from Genetic Engineering to Green Applications, $1^{\text {st }}$ ed.; Elsevier: Amsterdam, 2014. 
16. Klaochanpong, N.; Puttanlek, C.; Rungsardthong, V.; PunchaArnon, S.; Uttapap, D.; Food Hydrocolloids 2015, 45, 218.

17. Li, X.; Xia, Y.; Gao, W.; Jiang, Q.; Guo, H.; Cao, J.; Huang, L.; Xiao, P.; Food Hydrocolloids 2014, 40, 196.

18. Mali, S.; Grossmann, M. V. E.; Yamashita, F.; Semina: Ciênc. Agrár. 2010, 31, 137.

19. Hoffmann, I.; Silva, V. D.; Nascimento, M. G.; J. Braz. Chem. Soc. 2011, 22, 1559.

20. Barreiro, E. J.; Ferreira, V. F.; Costa, P. R. R.; Quim. Nova 1997, $20,647$.

21. Nguyen, L. A.; He, H.; Pham-Huy, C.; Int. J. Biomed. Sci. 2006, 2,85 .

22. Mai, N. L.; Ahn, K.; Koo, Y.-M.; Process Biochem. 2014, 49, 872.

23. Moniruzzaman, M.; Nakashima, K.; Kamiya, N.; Goto, M.; Biochem. Eng. J. 2010, 48, 295.

24. Nascimento, M. G.; da Silva, J. M. R.; da Silva, J. C.; Alves, M. M.; J. Mol. Catal. B: Enzym. 2015, 1.

25. Naushad, M.; AlOthman, Z. A.; Khan, A. B.; Ali, M.; Int. J. Biol. Macromol. 2012, 51, 555.

26. Brady, D.; Reddy, S.; Mboniswa, B.; Steenkamp, L. H.; Rousseau, A. L.; Parkinson, C. J.; Chaplin, J.; Mitra, R. K.; Moutlana, T.; Marais, S. F.; Gardiner, N. S.; J. Mol. Catal. B: Enzym. 2012, 75, 1.

27. Zheng, G.-W.; Yu, H.-L.; Li, C.-X.; Pan, J.; Xu, J.-H.; J. Mol. Catal. B: Enzym. 2011, 70, 138.
28. Morita, T.; Manual de Soluções, Reagentes e Solventes Padronização, Preparação, Purificação, Indicadores de Segurança, Descarte de Produtos Químicos; Edgard Blucher: São Paulo, 2007.

29. da Silva, J. M. R.; Nascimento, M. G.; Quim. Nova 2014, 37, 1022.

30. Wang, D.-L.; Nag, A.; Lee, G.-C.; Shaw, J.-F.; J. Agric. Food Chem. 2002, 50, 262.

31. Herbst, D.; Peper, S.; Niemeyer, B.; J. Biotechnol. 2012, 162, 398.

32. Laane, C.; Boeren, S.; Vos, K.; Veeger, C.; Biotechnol. Bioeng. 1987, 30, 81 .

33. Pilissão, C.; Carvalho, P. O.; Nascimento, M. G.; J. Braz. Chem. Soc. 2010, 21, 973.

34. Van Rantwijk, F.; Sheldon, R. A.; Chem. Rev. 2007, 107, 2757.

35. da Silva, J. M. R.; Nascimento, M. G.; Process Biochem. 2012, 47, 517.

36. Kohlmann, C.; Robertz, N.; Leuchs, S.; Dogan, Z.; Lütz, S.; Bitzer, K.; Na'amnieh, S.; Greiner, L.; J. Mol. Catal. B: Enzym. 2011, 68, 147.

37. Yuan, Y.; Bai, S.; Sun, Y.; Food Chem. 2006, 97, 324.

Submitted: February 15, 2016

Published online: April 15, 2016 